\title{
A Concept for a Novel Test for Chemical Parity
}

\author{
Heinz Langhals*, Oswald Krotz \\ Department of Chemistry, LMU University of Munich, Munich, Germany \\ Email: *Langhals@lrz.uni-muenchen.de
}

How to cite this paper: Langhals, H. and Krotz, O. (2018) A Concept for a Novel Test for Chemical Parity. Green and Sustainable Chemistry, 8, 311-319. https://doi.org/10.4236/gsc.2018.84021

Received: August 17, 2018

Accepted: October 26, 2018

Published: October 29, 2018

Copyright (C) 2018 by authors and Scientific Research Publishing Inc. This work is licensed under the Creative Commons Attribution International License (CC BY 4.0).

http://creativecommons.org/licenses/by/4.0/

\begin{abstract}
Deviations from chemical parity (PV) were evaluated with the search for very small enantiomeric excesses in a racemate prepared from non chiral materials and were detected by means of the circular dichroism (CD). Thus, intensely light-absorbing perylenebiscarboximides were attached to axially chiral biphenyls for the amplification of CD effects by exciton interactions of the adjacent chromophores. A rapidly racemising system was applied for the exclusion of artifacts and compared with an analogous with locked chirally. A very slight enantiomeric excess was detected for the $(M)$ enantiomer. Application of the method for other systems was suggested and relations to natural products discussed.
\end{abstract}

\section{Keywords}

Chirality, Parity, Circular Dichroism, UV/Vis Spectroscopy, Racemates

\section{Introduction}

Nature handles chemical substances and processes remarkably sustainable where the chirality of natural products is dominant contrasting the majority of synthetic technical materials. Neither the reason for the preference of chirality nor the mostly strict preference of one enantiomer in natural products is clarified because the equivalence of both enantiomers concerning achiral, scalar properties is claimed by parity. The exact validity of parity is generally accepted for preparative chemistry [1] [2] [3] [4]. Thus, stereogenic centres generated from achiral starting materials under achiral conditions are expected to form racemates of an exact 1:1 composition of the enantiomers. The theoretically predicted [5] and experimentally verified [6] deviations from parity for weak interactions of elemental particles induced a discussion [7] [8] [9] [10] [11] if there are also very small deviations from parity in chemistry. Attempts of a direct measurement of deviations from the 1:1 composition of racemates formed from 
achiral material have not been successful; the therefore necessary measurement of extremely small differences of high concentrations seems to be an extraordinarily difficult problem for chemical analytics. Moreover, chiral contaminations as a consequence of contact with the biosphere may cause artifacts such as arbitrary optical induction in the syntheses of racemates or kinetic or chromatographic resolution, such as by traces of bio materials adsorbed at surfaces. Research is now concentrated to indicate small differences of scalar properties of enantiomers with essentially four concepts: Firstly measurements of differences in IR frequencies [12]-[17] and rotational spectra [18] of enantiomers of small molecules, secondly the indication of different IR-CD effects of enantiomers [19], and thirdly the different coiling of enantiomeric polymers [20]. Any chiral contamination of samples remains the main problem for the latter. Fourthly, a detection by CD spectra (circular dichroism) of simple derivatives of ammonia were suggested [21]. As a consequence, a novel concept would bring about progress in this fundamental discussion.

\section{Experimental}

\subsection{Spectroscopy}

IR spectra: Perkin Elmer 1420 Ratio Recording Infrared Spektrometer, FT 1000; UV/Vis spectra: Varian Cary 5000 and Bruins Omega 20; fluorescence spectra: Perkin Elmer FS 3000 (totally corrected); CD spectroscopy: Jasco J810 Spectrapolarimeter, spectral bandwidth $0.5 \mathrm{~nm}$, integration time 0.5 and $1 \mathrm{~s}$, data interval $0.2 \mathrm{~nm}$; NMR spectroscopy: Varian Vnmrs 600 (600 MHz); mass spectrometry: Finnigan MAT 95.

\subsection{Chemicals}

(1,1'-Biphenyl)-2,2'-diamine (1, RN 1454-80-4), was supplied from Sigma-Aldrich (product No. 727601) and imidazole (RN 288-32-4) from BASF. Perylene-3,4,9,10-tetracarboxylic-3,4-anhydride-9,10-(1-hexylheptylimide) was prepared according to the literature [22].

2-(1-Hexylheptyl)-9-\{2'-[6-(1-hexylheptyl)anthra[2,1,9-def,6,5,10-d'e'f]di isoquinoline-1,3,8,10-tetraone-2-yl]diphenyl-2-yl\}anthra[2,1,9-def,6,5,10-d'e'f] diisoquinoline-1,3,8,10-tetraone (3): Perylene-3,4,9,10-tetracarboxylic-3,4-anhydride-9,10-(1-hexylheptylimide) $(2,212 \mathrm{mg}, 369 \mu \mathrm{mol})$ [22] and (1,1'-biphenyl)-2,2'-diamine $(1,34 \mathrm{mg}, 185 \mu \mathrm{mol})$ in imidazole $(1 \mathrm{~g})$ were heated with the exclusion of air and moisture (Ar atmosphere) for $5 \mathrm{~h}$ at $140^{\circ} \mathrm{C}$, diluted with ethanol after cooling $(10 \mathrm{~mL})$, precipitated with $2 \mathrm{~m}$ aqueous $\mathrm{HCl}(20 \mathrm{~mL})$, stirred for $1 \mathrm{~h}$, collected by vacuum filtration and purified by column separation (silica gel, chloroform to remove a forerun and then silica gel, chloroform/ethanol 20:1 for the main fraction). Yield $111 \mathrm{mg}(46 \%)$ dark red solid, $R_{f}$ (silica gel, chloroform/ethanol 20:1): 0.29, IR $(\mathrm{KBr}): \tilde{v}=2923.6(\mathrm{~m}), 2854.5$ (m), 1695.5 (m), 1655.2 (s), 1592.0 (s), $1577.0(\mathrm{~m}), 1505.7(\mathrm{w}), 1480.6(\mathrm{w}), 1432.9$ (w), $1403.9(\mathrm{~m}), 1337.8(\mathrm{~s}), 1249.9(\mathrm{~m}), 1174.2(\mathrm{w}), 1124.7(\mathrm{w}), 1105.9(\mathrm{w}), 964.2$ 
(w), $847.9(\mathrm{w}), 808.5(\mathrm{~m}), 744.6(\mathrm{~m}), 637.4 \mathrm{~cm}^{-1}(\mathrm{w}),{ }^{1} \mathrm{H}$ NMR (600 $\mathrm{MHz}, \mathrm{CDCl}_{3}$, $\left.25^{\circ} \mathrm{C}\right): \delta=0.82-0.92\left(\mathrm{~m}, 12 \mathrm{H}, \mathrm{CH}_{3}\right), 1.22-1.49\left(\mathrm{~m}, 32 \mathrm{H}, \mathrm{CH}_{2}\right), 1.92-2.04(\mathrm{~m}$, $\left.4 \mathrm{H}, \beta-\mathrm{CH}_{2}\right), 2.25-2.35\left(\mathrm{~m}, 4 \mathrm{H}, \alpha-\mathrm{CH}_{2}\right), 5.22-5.24(\mathrm{~m}, 2 \mathrm{H}, \alpha-\mathrm{CH}), 7.24-7.25$ $(\mathrm{m}, 2 \mathrm{H}$, arom. CH), $7.47-7.50(\mathrm{~m}, 2 \mathrm{H}$, arom. $\mathrm{CH}), 7.69-72(\mathrm{~m}, 2 \mathrm{H}$, arom. $\mathrm{CH}), 7.79-7.80(\mathrm{~m}, 2 \mathrm{H}$, arom. $\mathrm{CH}), 8.13-8.51 \mathrm{ppm}(\mathrm{m}, 16 \mathrm{H}$, arom. $\mathrm{CH}),{ }^{13} \mathrm{C}$ NMR (151 MHz, $\left.\mathrm{CDCl}_{3}, 25^{\circ} \mathrm{C}\right): \delta=14.3,22.9,27.2,29.5,32.0,2.1,32.5,32.7$, $55.1,122.7,122.9,123.0,123.3,123.4,124.0,124.3,126.1,126.5,128.9,129.0$, $129.2,129.3,129.6,130.9,131.8,133.5,133.8,134.1,134.3,134.7,134.8,138.2$, 162.8, 163.8, $164.2 \mathrm{ppm}, \mathrm{UV} / \mathrm{Vis}\left(\mathrm{CHCl}_{3}\right): \lambda_{\max }(\varepsilon)=262(63,400), 461(37,400)$, $492(102,900), 533 \mathrm{~nm}\left(152,200 \mathrm{~L} \cdot \mathrm{mol}^{-1} \cdot \mathrm{cm}^{-1}\right)$, fluorescence $\left(\mathrm{CHCl}_{3}\right): \lambda_{\max }=539$, $582 \mathrm{~nm}$, fluorescence quantum yield $\left(\mathrm{CHCl}_{3}, \lambda_{\text {ex }}=490 \mathrm{~nm}, E_{490 \mathrm{~nm}}=0.240 \mathrm{~cm}^{-1}\right.$, reference [23]: 2,9-Bis-(1-hexylheptyl)anthra[2,1,9-def,6,5,10-d'e'f]diisoquinoline-1,3,8,10-tetraone, RN 110590-84-6 [24], with $\Phi=1.00): 1.00, \mathrm{MS}_{\left(\mathrm{DEI}^{+} / 70\right.}$ $\mathrm{eV}): \mathrm{m} / \mathrm{z}$ (\%): 1294 (4) [ $\left.M^{+}\right], 931$ (39), 182 (38), 97 (42), 83 (61), 69 (100), 55 (91), 44 (24). $\mathrm{C}_{86} \mathrm{H}_{78} \mathrm{~N}_{4} \mathrm{O}_{8}$ (1295.6): calcd. C 79.73, H 6.07, N 4.32; found C 79.26, H 6.26, N 4.26 .

\section{Results and Discussion}

The detection of an utmost only very small enantiomeric excess in essentially racemic materials as a consequence of a possible chemical violation of parity (PV) requires an analytical signal amplification. We applied optical circular dichroism (CD) [25] as the difference of light absorptivity between left and right circularly polarized light for the detection of a chiral fraction where the effect would be completely compensated for an exact 1:1 racemate. Chiral substituents or chiral media generally induce only very weak CD effects in achiral, flat chromophores such as the perylene dyes; this makes CD spectroscopy of such dyes insensitive and robust concerning traces of chiral contaminants of biological origin. However, very strong CD effects were induced by exciton interactions of adjacent chromophores in chiral arrangements in dyads so that the required high signal amplifications are obtained. Furthermore, special care has to be taken for the exclusion of other possible artifacts such as arbitrary kinetic or chromatographic partial resolution of racemates in chemical synthesis and workup of such chiral arrangements. For this reason, we applied permanently fast racemising [26] [27] [28] [29] axially chiral 2,2'-substituted biphenyls [30] [31] with chiral half-lifes in the order of minutes [32] [33] [34] [35] [36].

Perylene biscarboximides [37] [38] with the solubilizing swallow-tail $N$-substituent 1-hexylheptyl [24] [37] were used as the required chromophores for the preparation of the target compound, because of only a single electronic transition [39] in the visible polarized along the $N$-N-connection line [40], the strong fluorescence [23] and high chemical persistency [37]. Thus, we condensed [41] 2,2'-diaminobiphenyl (1) with the anhydride carboximide 2 [22] to form the racemic bichromophore $(P)-3$ and $(M)-3$; see Scheme 1. 


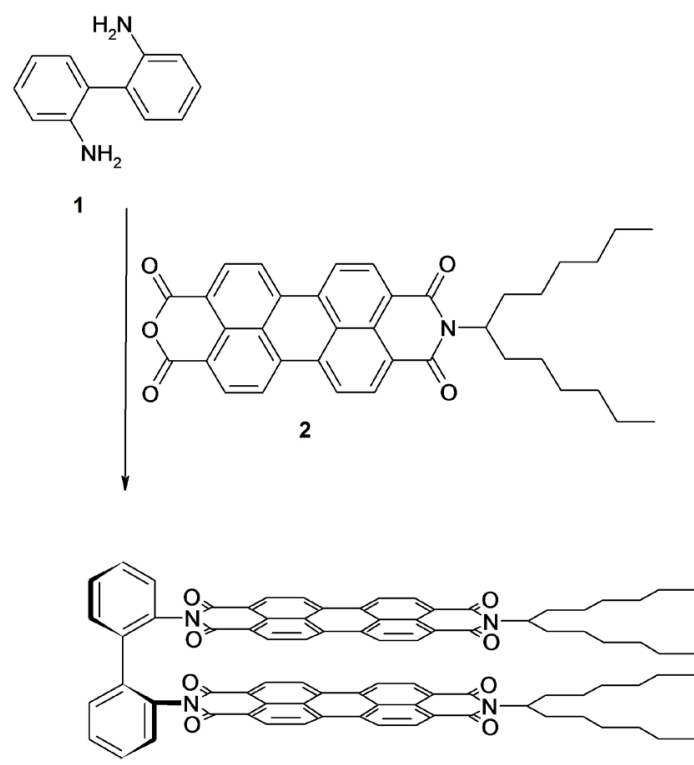

(P)-3

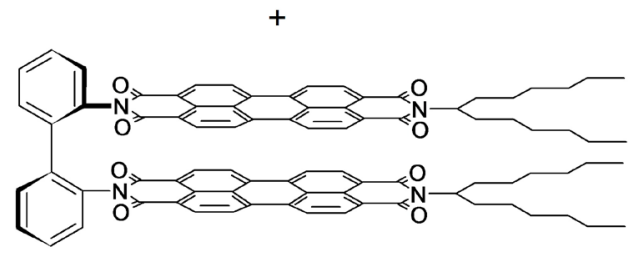

(M)-3

Scheme 1. Synthesis of 3.

The achiral chromophore of perylenebiscarboximides as a component in $\mathbf{3}$ such as in the soluble derivative 4 (see Scheme 2, top) exhibits a strongly structured intense UV/Vis- absorption with a maximum at $526 \mathrm{~nm}$ and a molar absorptivity of $88,000 \mathrm{~L} \cdot \mathrm{mol} \cdot \mathrm{cm}^{-1}$ in the maximum [42] as is indicated in Figure 1, left, bottom. We sterically locked the chirality in the biphenyl dyad 3 with methyl groups to obtain the pure, stable atrop enantiomers $(P)-5$ and $(M)-5$ [43] where exciton effects of the adjacent chromophores both influence the UV/Vis absorption spectra (see Figure 1, left, middle; the spectrum of $(P)-5$ is identical) and induce very strong $\mathrm{CD}$ effects of absolute $\varepsilon$ values of about 500 (see Figure 1, left, top); these high exciton-induced $\mathrm{CD}$ effects were used as an amplifier for the detection of a chiral fraction in 3. One can expect similarly high CD effects in the unlocked, demethylated 3 in the same spectral region because of a similar arrangement of chromophores (the electronic effect of the methyl groups in $\mathbf{5}$ on the chromophore are estimated to be unimportant; compare [43] [44]); however, a fast racemization proceeds to an equilibrium because of the low torsion barrier in the unlocked 3; this excludes artefacts such as by arbitrary chromatographic resolution at chiral surfaces. There will be a compensation of CD effects of $(P)-3$ and $(M)-3$ in the racemate so that only an enantiomeric excess will be detected in the CD spectrum of such a dynamic racemate. We found very weak concentration-dependent $\mathrm{CD}$ signals of $\mathbf{3}$ in the expected spectral region where strong 

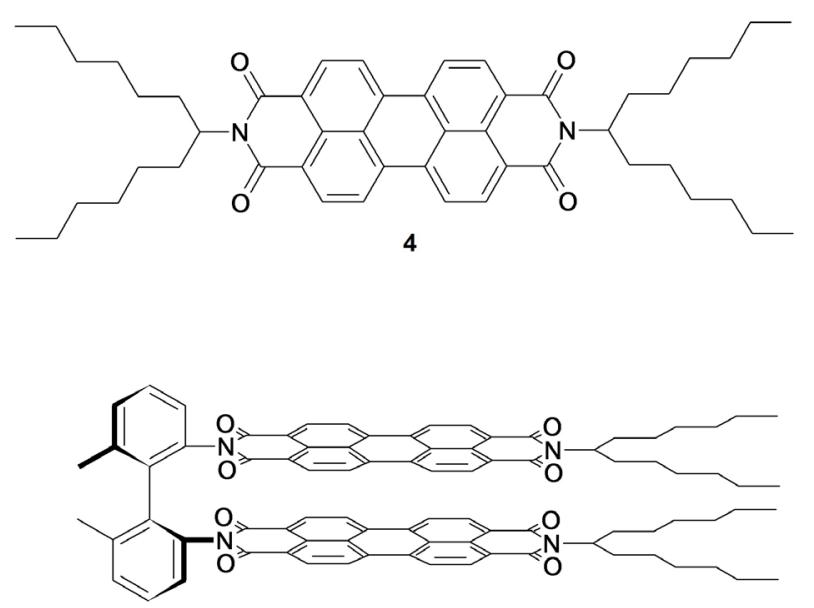

(P)-5

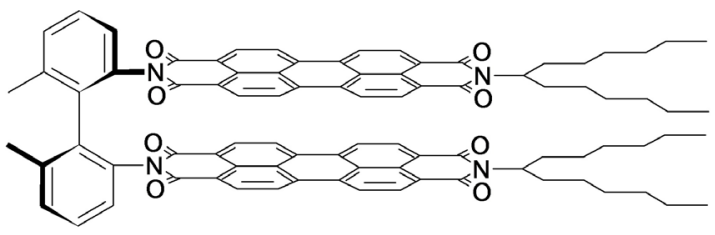

(M)-5

Scheme 2. The achiral dye S-13 (4) and the sterically locked, stable chiral atropisomeric dyes $(P)-5$ and $(M)-5$, for comparing CD effects.

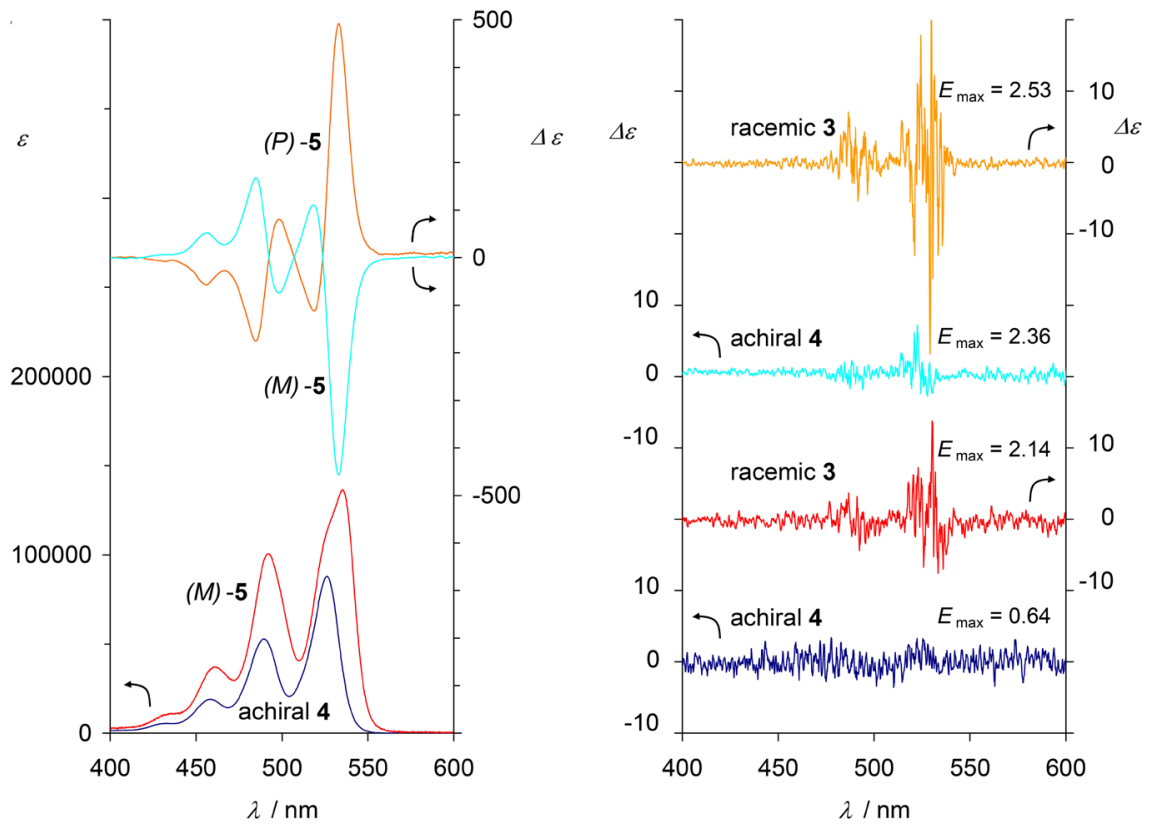

Figure 1. Left from bottom to top: UV/Vis spectra of 4 (blue), $(M)-5$ (red), and the CD spectra of $(P)-5$ (orange) and $(M)-5$ (turquoise) for indicating the CD effect of perylenes in sterically locked biphenyls. Right from bottom to top: CD spectra of 4 (blue, $E_{\max / 1 \mathrm{~cm}}=$ 0.64 ), 3 (red, $E_{\max / 1 \mathrm{~cm}}=2.14$ ), 4 (turquoise, more concentrated: $E_{\max / 1 \mathrm{~cm}}=2.36$ ), 3 (orange, more concentrated: $E_{\max / 1 \mathrm{~cm}}=2.53$ ) indicating a very small enantiomeric excess for $(M)$-3. All spectra were recorded in chloroform. 
signals of the pure enantiomers of $\mathbf{5}$ were found. These were attributed to a very small enantiomeric excess of the $(M)$-3 enantiomer where the concentration dependence may be taken as an indicator for a dye specific effect (a further increase of the concentration and the optical density $E$, respectively, is problematic because of the strong light absorption). Controlling the proper function of the spectrometer, we recorded the spectra of the achiral and in the same spectral region analogically absorbing 4 at similar optical densities and did not get comparably intense $\mathrm{CD}$ signals. As a consequence, the $\mathrm{CD}$ spectra of $\mathbf{3}$ can be taken as an indicator for a very small enantiomeric excess of $(M)-3$.

\section{Conclusion}

A fast racemizing ensemble of enantiomers may be a useful tool for the detection of a spontaneous formation of an enantiomeric excess where atropisomeric biphenyls are of special interest because the rate of racemisation can be efficiently controlled by steric effects of substituents. Amplifying the detection sensitivity of enantiomeric excesses is necessary because of the small expected effects. Optical methods, preferentially the measurement of strong $\mathrm{CD}$ effects induced by exciton interactions of adjacent chromophores, are attractive because of high sensitivity. The investigation of a perylene dyad of biphenyl indicated a very small enantiomeric excess of the $(M)$ enantiomer. One can speculate about the origin of the preference. The well-known parity-violating (PV) asymmetry for weak interactions seems to be very small concerning chemistry; the present study indicates a much larger effect where the order of magnitude might become important for living organisms. This may find its counterpart in the general clear preference each for one individual enantiomer in the biosphere. Finally, exciton interactions of larger chromophores such as $\mathbf{4}$ in racemizing systems may be an attractive, efficient and sensitive tool for the investigation of chiral effects and search for other examples for PV.

\section{Acknowledgements}

This work is supported by the Fonds der chemischen Industrie and the CIPSM Cluster in Munich.

\section{Conflicts of Interest}

The authors declare no conflicts of interest regarding the publication of this paper.

\section{References}

[1] Sofikitis, D., Bougas, L., Katsoprinakis, G.E., Spiliotis, A.K., Loppinet, B. and Rakitzis, T.P. (2014) Evanescent-Wave and Ambient Chiral Sensing by Signal-Reversing Cavity Ringdown Polarimetry. Nature, 514, 76-79. https://doi.org/10.1038/nature13680

[2] Quack, M. (1989) Structure and Dynamics of Chiral Molecules. Angewandte Chemie International Edition, 28, 571-586. https://doi.org/10.1002/anie.198905711

[3] Saleh, N., Zrig, S., Roisnel, T., Guy, L., Bast, R., Saue, T., Darquie, B. and Crassous, 
J. (2013) A Chiral Rhenium Complex with Predicted High Parity Violation Effects: Synthesis, Stereochemical Characterization by VCD Spectroscopy and Quantum Chemical Calculations. Physical Chemistry Chemical Physics, 15, 10952-10959. https://doi.org/10.1039/c3cp50199j

[4] van't Hoff, J.H. (1887) La chimie dans l'éspace, Rotterdam. In: Bourgeois, C., Ed., Sur la dissymétrie moléculaire, Collection Epistème, Paris.

[5] Lee, T.D. and Yang, C.N. (1956) Question of Parity Conservation in Weak Interactions. Physical Review Journals Archive, 104, 254-258. https://doi.org/10.1103/PhysRev.104.254

[6] Wu, C.S., Ambler, E., Hayward, R.W., Hoppes, D.D. and Hudson, R.P. (1957) Experimental Test of Parity Conservation in $\beta$-Decay. Physical Review Journals Archive, 105, 1413-1415. https://doi.org/10.1103/PhysRev.105.1413

[7] Quack, M. (2002) How Important Is Parity Violation for Molecular and Biomolecular Chirality? Angewandte Chemie International Edition, 41, 4618-4630. https://doi.org/10.1002/anie.200290005

[8] Crassous, J., Monier, F., Dutasta, J.-P., Ziskind, M., Daussy, C., Grain, C. and Chardonnet, C. (2003) Search for Resolution of Chiral Fluorohalogenomethanes and Parity-Violation Effects at the Molecular Level. ChemPhysChem, 4, 541-548. https://doi.org/10.1002/cphc.200200536

[9] Elitzur, A.C. and Shinitzky, M. (2006) P-Violation Manifested at the Molecular Level-A Simple Means for an Absolute Definition of "Left" vs. "Right". Chemical Abstracts, 144, Article ID: 241270.

[10] Quack, M. and Stohner, J. (2006) Physikalische Chemie 2005. Nachrichten aus der Chemie, 54, 282-291.

[11] Quack, M. (2018) Quantum Dynamics of Chiral Molecules Including Electroweak Parity Violation: From High Resolution Spectroscopy towards Fundamental Symmetries and Asymmetries. 255th ACS National Meeting \& Exposition, New Orleans, LA, United States, 18-22 March 2018.

[12] Viglione, R.G. (2004) Theoretical Determination of Parity-Violating Vibrational Frequency Differences between the Enantiomers of Chiral Molecules. The Journal of Chemical Physics, 121, 9959-9963. https://doi.org/10.1063/1.1807815

[13] Quack, M. and Stohner, J. (2003) Combined Multidimensional Anharmonic and Parity Violating Effects in CDBrClF. The Journal of Chemical Physics, 119, 11228-11240. https://doi.org/10.1063/1.1622381

[14] Gottselig, M. and Quack, M. (2005) Steps towards Molecular Parity Violation in Axially Chiral Molecules. I. Theory for Allene and 1,3-Difluoroallene. The Journal of Chemical Physics, 123, Article ID: 084305. https://doi.org/10.1063/1.1884114

[15] Quack, M. and Willeke, M. (2006) Stereomutation Tunneling Switching Dynamics and Parity Violation in Chlorineperoxide Cl-O-O-Cl. The Journal of Physical Chemistry A, 110, 3338-3348. https://doi.org/10.1021/jp055770h

[16] Schwerdtfeger, P., Laerdahl, J.K. and Chardonnet, C. (2002) Calculation of Parity-Violation Effects for the C-F Stretching Mode of Chiral Methyl Fluorides. Physical Review A: Atomic, Molecular, and Optical Physics, 65, Article ID: 042508. https://doi.org/10.1103/PhysRevA.65.042508

[17] Crassous, J., Chardonnet, C., Saue, T. and Schwerdtfeger, P. (2005) Recent Experimental and Theoretical Developments towards the Observation of Parity Violation (PV) Effects in Molecules by Spectroscopy. Organic \& Biomolecular Chemistry, 3, 2218-2224. https://doi.org/10.1039/b504212g 
[18] Bunker, P.R. and Jensen, P. (2004) Chirality in Rotational Energy Level Clusters. Journal of Molecular Spectroscopy, 228, 640-644. https://doi.org/10.1016/j.jms.2004.02.027

[19] Soulard, P., Asselin, P., Cuisset, A., Aviles, M.J.R.T., Huet, R., Petitprez, D., Demaison, J., Freedman, T.B., Cao, X., Nafie, L.A. and Crassous, J. (2006) Chlorofluoroiodomethane as a Potential Candidate for Parity Violation Measurements. Physical Chemistry Chemical Physics, 8, 79-92. https://doi.org/10.1039/B510675C

[20] Scolnik, Y., Portnaya, I., Cogan, U., Tal, S., Haimovitz, R., Fridkin, M., Elitzur, A.C., Deamer, D.W. and Shinitzky, M. (2006) Subtle Differences in Structural Transitions between Poly-l- and Poly-d-amino Acids of Equal Length in Water. Physical Chemistry Chemical Physics, 8, 333-339. https://doi.org/10.1039/B513974K

[21] MacDermott, A.J.R. and Hegstrom, A. (2004) A Proposed Experiment to Measure the Parity-Violating Energy Difference between Enantiomers from the Optical Rotation of Chiral Ammonia-Like "Cat" Molecules. Chemical Physics, 305, 55-68. https://doi.org/10.1016/j.chemphys.2004.06.017

[22] Kaiser, H., Lindner, J. and Langhals, H. (1991) Synthesis of Nonsymmetrically Substituted Perylene Fluorescent Dyes. Chemische Berichte, 124, 529-535. https://doi.org/10.1002/cber.19911240319

[23] Langhals, H., Karolin, J. and Johansson, L.B.-Å. (1998) Spectroscopic Properties of New and Convenient Standards for Measuring Fluorescence Quantum Yields. Journal of the Chemical Society, Faraday Transactions, 94, 2919-2922.

[24] Langhals, H., Demmig, S. and Potrawa, T. (1991) The Relation between Packing Effects and Solid State Fluorescence of Dyes. Journal für Praktische Chemie, 333, 733-748. https://doi.org/10.1002/prac.19913330508

[25] Nakanishi, K. and Berova, N. (1994) The Excitation Chirality Method (Circular Dichroism. Principles and Their Applications). VCH Verlagsgesellschaft, Weinheim.

[26] Wolf, C., Koenig, W.A. and Roussel, C. (1995) Conversion of a Racemate into a Single Enantiomer in One Step by Chiral Liquid Chromatography: Studies with Rac-2,2'-diiodobiphenyl. Chirality, 7, 610-611.

[27] Jung, M., Fluck, M. and Schurig, V. (1994) Enantiomerization of 2,2'-diisopropylbiphenyl during Chiral Inclusion Gas Chromatography: Determination of the Rotational Energy Barrier by Computer Simulation of Dynamic Chromatographic Elution Profiles. Chirality, 6, 510-512.

[28] Hammerschmidt, E. and Voegtle, F. (1980) Internal Mobility of Open-Chain Oligophenyl Compounds. Chemische Berichte, 113, 1121-1124.

[29] Charton, M. (1977) Steric Effects. 8. Racemization of Chiral Biphenyls. The Journal of Organic Chemistry, 42, 2528-2529.

[30] Kuhn, R. and Albrecht, O. (1927) Stereochemistry of Aromatic Compounds. IV. Racemization of Optically Active Diphenic Acids and the Oscillation of the Benzine Nucleus in the Diphenyl System. Liebigs Annalen der Chemie, 455, 272-299.

[31] Prelog, V. and Helmchen, G. (1982) Bases of the CIP System and Proposal for a Revision. Angewandte Chemie, 94, 614-631. https://doi.org/10.1002/anie.198205671

[32] Cook, D.E. and Turner, E.E. (1937) Racemization of Some d-o-(2-Dimethylaminophenyl)Phenyltrimethylammonium Salts. Journal of the Chemical Society, 88-89.

[33] Adams, R. and Snyder, H.R. (1938) Stereochemistry of Biphenyls. XLIII. Effect of Substituents in the 4-Position of 2-Nitro-6-Carboxy-2'-Methylbiphenyl. Journal of 
the American Chemical Society, 60, 1411-1415.

[34] Adams, R. and Hale, J.B. (1939) Stereochemistry of Biphenyls. XLVIII. Comparison of the Racemization Rates of Three Isomeric 2,2',6-nitro-, carboxy-, Methyl-Biphenyls. Journal of the American Chemical Society, 61, 2825-2828.

[35] Bell, F. and Robinson, P.H. (1927) Diphenyl Series. VII. The Relative Stability of Optically Active Diphenic Acids. Journal of the Chemical Society, 2234-2239.

[36] Theilacker, W. and Boehn, H. (1967) Optically Active 2,2'-Dimethylbiphenyl, the Simplest Atropisomeric Hydrocarbon. Angewandte Chemie International Edition, 6, 251.

[37] Langhals, H. (2005) Control of the Interactions in Multichromophores: Novel Concepts. Perylene Bis-Imides as Components for Larger Functional Units. Helvetica Chimica Acta, 88, 1309-1343. https://doi.org/10.1002/hlca.200590107

[38] Langhals, H. (1995) Cyclic Carboxylic Imide Structures as Structure Elements of High Stability. Novel Developments in Perylene Dye Chemistry. Heterocycles, 40, 477-500. https://doi.org/10.3987/REV-94-SR2

[39] Nakamura, S., Murakami, A., Adachi, M. and Irie, M. (1996) A New Guiding Principle towards the Spectral Design of Organic Functional Molecules. Pure and Applied Chemistry, 68, 1441-1442. https://doi.org/10.1351/pac199668071441

[40] Johansson, L.B.-Å. and Langhals, H. (1991) Spectroscopic Studies of Fluorescent Perylene Dyes. Spectrochimica Acta, 47A, 857-861.

https://doi.org/10.1016/0584-8539(91)80272-K

[41] Langhals, H. (1985) Synthesis of Highly Pure Perylene Fluorescent Dyes in Large Scale Amounts-Specific Preparation of Atropic Isomers. Chemische Berichte, 118, 4641-4645. https://doi.org/10.1002/cber.19851181138

[42] Demmig, S. and Langhals, H. (1988) Readily Soluble Lightfast Perylene Dyes. Chemische Berichte, 121, 225-230. https://doi.org/10.1002/cber.19881210205

[43] Langhals, H., Hofer, A., Bernhard, S., Siegel, J.S. and Mayer, P. (2011) Axially Chiral Bichromophoric Fluorescent Dyes. The Journal of Organic Chemistry, 76, 990-992. https://doi.org/10.1021/jo102254a

[44] Langhals, H. and Gold, J. (1997) Chiral Bifluorophoric Perylene Dyes with Unusually High CD Effects. A Simple Model for the Photosynthesis Reaction Center. Liebigs Annalen, 1151-1153. https://doi.org/10.1002/jlac.199719970615 